\title{
Expression of epidermal growth factor and transforming growth factor $\alpha$ in interfacial membranes retrieved at revision total hip arthroplasty
}

Jing-Wen Xu, Jian Ma, Tian-Fang Li, Eero Waris, Anne Alberty, Seppo Santavirta, Yrjö T Konttinen
Institute of

Biomedicine,

Department of

Anatomy, University of

Helsinki, Finland

J-W Xu

$\mathrm{J} \mathrm{Ma}$

T-F Li

E Waris

Y T Konttinen

Department of

Orthopaedics and

Traumatology,

Helsinki University

Central Hospital,

Helsinki, Finland

J-W Xu

A Alberty

S Santavirta

Department of Oral Medicine, Helsinki

University Central

Hospital,

Y T Konttinen

Division of

Rheumatology, Long

Island Jewish Medical

Center, New Hyde

Park, NY, USA

J-W Xu

Correspondence to:

Professor Yrjö T Konttinen,

Department of Oral

Medicine, Surgical Hospital,

Kasarmikatu 11-13,

FIN-00029, Helsinki

University Central Hospital,

Helsinki, Finland

Email:

yrjo.konttinen@helsinki.fi

Accepted for publication

17 February 2000

\begin{abstract}
Background-The interfacial membrane between bone and implant has been shown to be a key tissue in the process of aseptic loosening of total hip arthroplasty. The cells within the interfacial membrane produce numerous inflammatory mediators which, through complex mechanisms, cause periprosthetic osteolysis and aseptic loosening. Both epidermal growth factor (EGF) and transforming growth factor $\alpha(\mathrm{TGF} \alpha)$ have similar biological functions. They have been found to stimulate bone resorption.
\end{abstract}

Objective-To investigate the presence, cellular localisation, and extent of expression of EGF and TGFa in interfacial membrane retrieved from revision total hip arthroplasty and compare it with that in synovial membrane from primary total hip arthroplasty.

Methods-Ten interfacial membranes and 10 synovial membranes were stained with avidin-biotin-peroxidase complex for EGF and TGF $\alpha$. The staining process was done using the Lab Vision Autostainer. The results were measured by a semiautomatic VIDAS image analysis system.

Results-Immunoreactivity for both EGF and TGF $\alpha$ was found in the endothelial cells of blood vessels, macrophages, and fibroblasts, both in interfacial membranes and synovial membranes. However, the number of EGF (980 (370)) and TGFa (1070 (360)) positive cells per $\mathrm{mm}^{2}$ was greater in interfacial membranes than in the synovial membranes (220 (200), 270 (100); p<0.01).

Conclusion-It is suggested that owing to their increased expression in interfacial membrane, EGF and TGF $\alpha$ may have an important pathogenetic role in stimulating periprosthetic bone resorption in aseptic loosening of total hip arthroplasty. (Ann Rheum Dis 2000;59:822-827)

When hip prostheses are revised owing to aseptic loosening, a layer of interfacial membrane between bone and prosthesis can almost always be found. Because this membrane can release a variety of inflammatory mediators ${ }^{1-6}$ and is present where bone is resorbed, it must participate in the bone resorption process and contribute to aseptic loosening. It is generally accepted that wear debris generated from a prosthesis is phagocytosed by macrophages/ foreign body giant cells and subsequently activates these cells to release a variety of mediators that can stimulate osteoclastic bone resorption to provoke a cascade leading to aseptic loosening. ${ }^{3-13}$ Other factors, such as mechanical factors, may also have an important role in aseptic loosening.

Epidermal growth factor (EGF) was one of the first cytokines to be identified, originally isolated from male mouse submandibular glands. ${ }^{14}$ Transforming growth factor $\alpha$ $(\mathrm{TGF} \alpha)$ is a secreted polypeptide that was first isolated from murine sarcoma virus transformed fibroblast cultures. ${ }^{15}$ Both EGF and TGF $\alpha$ bind to the same receptor with similar affinity, ${ }^{16}$ and biological responses caused by these two cytokines are, in most cases, similar. ${ }^{17}{ }^{18} \mathrm{EGF}$ and TGF $\alpha$ are local regulators of bone metabolism and stimulate bone resorption. ${ }^{19-22}$

We investigated the presence, cellular localisation, and extent of expression of EGF and TGF $\alpha$ in interfacial membrane from a loose total hip arthroplasty obtained at revision operation and compared the findings with those in synovial membrane from primary total hip arthroplasty carried out owing to osteoarthritis (OA).

\section{Methods}

PATIENTS AND SAMPLES

Ten samples of the interfacial membranes between bone and prosthesis/cement were obtained at revision total hip arthroplasty performed for aseptic loosening at the Department of Orthopaedics and Traumatology of Helsinki University Central Hospital, Finland, between May 1996 and June 1997. In all patients, both the clinical and radiographic appearance suggested aseptic prosthetic loosening. All samples were taken from the place at which osteolysis was located. All the components removed were clinically unstable at the time of revision. Culture for both aerobic and anaerobic organisms was carried out on interfacial membranes at revision surgery, and all results were negative. There were no clinical, roentgenographic, or laboratory signs of infection in any case. Ten patients (six female, four male) with a mean age of 72.7 years (range 44-89) were studied. All total hip arthroplasties had originally been performed to treat primary OA. The mean time between 
primary arthroplasty and revision was 9.4 years (range 1-25). Table 1 presents clinical and demographic data of the patients.

For comparison, 10 synovial membranes were obtained from 10 patients with OA (six female, four male) undergoing primary total hip arthroplasty. Their mean age was 56.3 years (range 38-82).

All fresh samples were frozen in isopentane, embedded in OCT compound (Lab-Tek Products, Division of Miles Laboratories, Elkhart, IN, USA) and stored at $-20^{\circ} \mathrm{C}$ until used for immunohistochemistry.

IMMUNOHISTOCHEMISTRY

Staining was done using the Lab Vision Autostainer (Lab Vision Corporation, Fremont, California, USA). The protocol is described below:

Cryostat sections, $6 \mu \mathrm{m}$ thick, were fixed in $0.3 \% \mathrm{H}_{2} \mathrm{O}_{2}$ in absolute methanol to block endogenous peroxidase activity for 30 minutes at $22^{\circ} \mathrm{C}$. The sections were then incubated with (a) normal rabbit serum for EGF, normal horse serum for $\mathrm{TGF} \alpha$ (Vector Laboratory, Burlingame, CA, USA), diluted $1: 50$ in $20 \mathrm{mM}$ Tris-HCl, $150 \mathrm{mM} \mathrm{NaCl}, \mathrm{pH} 7.5$ (Tris buffered saline (TBS)) for 20 minutes at $22^{\circ} \mathrm{C}$; (b) polyclonal goat antihuman EGF IgG antibody (dilution 1:100, British BioTechnology, Oxford, UK) and monoclonal mouse antihuman TGF $\alpha$ IgG antibody (dilution 1:100, Calbiochem, CA, USA) for 30 minutes at $22^{\circ} \mathrm{C}$; (c) biotinylated rabbit antigoat IgG for EGF antibody, biotinylated horse antimouse IgG for TGF $\alpha$ antibody (dilution 1:100, Vector Laboratory, Burlingame, CA, USA) for 30 minutes at $22^{\circ} \mathrm{C}$; and (d) avidin-biotin-peroxidase complex (dilution 1:100, Vector Laboratory, Burlingame, CA, USA) for 30 minutes at $22^{\circ} \mathrm{C}$. Finally, the peroxidase binding sites were revealed with a combination of 3,3'-diaminobenzidine tetrahydrochloride and $\mathrm{H}_{2} \mathrm{O}_{2}$ (DAB substrate kit, Vector Laboratories, Burlingame, CA, USA) for five minutes at $22^{\circ} \mathrm{C}$. Between the two steps sections were washed three times in TBS, then dehydrated in a gradual ethanol series, cleared in xylene, and mounted manually with synthetic mounting medium (Diatex, Becker Industrifarg AB, Marsta, Sweden). Negative staining controls were obtained by omission of the primary antibody and use of normal rabbit

Table 1 Demographic and clinical data of patients with osteoarthritis operated on for aseptic loosening of total hip arthroplasty from whom interfacial membranes were available for epidermal growth factor and transforming growth factor a analysis

\begin{tabular}{rllrlll}
\hline Case & $\begin{array}{l}\text { Age } \\
\text { (years) }\end{array}$ & Sex & $\begin{array}{c}\text { Time to } \\
\text { revision } \\
\text { (years) }\end{array}$ & Type of prosthesis & $\begin{array}{l}\text { Type of } \\
\text { alloy }\end{array}$ & Fixation \\
\hline 1 & 77 & $\mathrm{~F}$ & 14 & Lubinus SPII & TiVAl & Cemented \\
2 & 63 & $\mathrm{~F}$ & 11 & Brunsvick & CoVAl & Cemented \\
3 & 85 & $\mathrm{~F}$ & 1 & Thompson & Vitalium & Cemented \\
4 & 60 & $\mathrm{M}$ & 2 & Lubinus SPII & TiVAl & Cemented \\
5 & 71 & $\mathrm{M}$ & 14 & Brunsvick & CoVAl & Cemented \\
6 & 85 & $\mathrm{~F}$ & 18 & Lubinus SPII & TiVAl & Cemented \\
7 & 44 & $\mathrm{M}$ & 6 & Link & CoCrMo & Cementless \\
8 & 83 & $\mathrm{M}$ & 1 & Lubinus SPII & TiVAl & Cemented \\
9 & 70 & $\mathrm{~F}$ & 2 & Osteonics & CoCrMo & Cementless \\
10 & 89 & $\mathrm{~F}$ & 25 & McKee-Farrar & CoCrMo & Cemented \\
\hline
\end{tabular}

${ }^{\star}$ TiVAl $=$ titanium-vanadium-aluminium alloy; $\mathrm{CoVAl}=$ cobalt-vanadium-aluminium alloy; $\mathrm{CoCrMo}=$ cobalt-chromium-molybdenum alloy. serum (for EGF) and the same isotype $\operatorname{IgG}$ serum (for $\mathrm{TGF} \alpha$ ) at the same concentration. One section from each specimen was incubated with the substrate only, to exclude the detection of endogenous peroxidase activity in endothelial cells.

Tissue structure and cellularity were examined in haematoxylin and eosin and immunohistochemically stained sections. Ultrahigh molecular weight polyethylene particulate debris was examined by polarised light microscopy. Haematoxylin and eosin staining and immunohistochemistry were performed on serial sections of membrane samples.

QUANTIFICATION OF IMMUNOHISTOCHEMICAL

STAINING

Positive cells in immunohistochemical staining were measured by image analysis. The number of EGF and TGF $\alpha$ positive cells was counted in five different high power fields $(\times 400)$ by a low light charge screen coupled to a 12-bit PC digital image camera (SensiCam, Kelheim, Germany), mounted on a Leitz Diaplan (Wetzlar, Germany) light microscope. This was linked to a semiautomatic soft image analysis and processing system (Soft Imaging Analysis System $\mathrm{GmbH}$, Germany) equipped with the VIDAS 3.0 programme (Soft Imaging Analysis System GmbH, Germany). To estimate the adequate sampling area, the number of EGF and TGF $\alpha$ positive cells was calculated in three representative samples in both study groups (interface, control) to obtain an estimate of the population mean for each. Using the formula:

$$
t=\frac{\bar{x}-\mu}{S E M}
$$

it was calculated that if at least five fields were counted, the mean value did not differ significantly $(p>0.05)$ from the population mean ( $t$ refers to $t$ statistics, $\bar{x}=$ the sample mean, $\mu=$ the population mean, SEM = standard error of the mean). Thus reliable morphometric results were obtained by calculating five randomly selected fields in each sample. Results are expressed as the number of EGF or TGF $\alpha$ positive cells per $\mathrm{mm}^{2}$ of tissue.

STATISTICAL ANALYSIS

Statistical software, BMDP-PC 7.01, was used to calculate the mean (SEM) dispersion of the data. Normality of the distributions was checked using Wilk's $W$ test. The significance of differences between means was analysed by the $t$ test.

\section{Results}

HISTOPATHOLOGICAL EVALUATION

Tissue structure and cellularity varied within one sample and among tissue samples from different patients. The histopathological features of the interfacial membrane ${ }^{1}$ (figs $1 \mathrm{~A}$ and B) were similar to those of synovial membrane from patients with OA (fig 1C). The interfacial tissues consisted mainly of macrophages and fibroblasts. T lymphocytes were found dispersed in the macrophage infiltrates in some specimens. Tissue necrosis was also often seen 


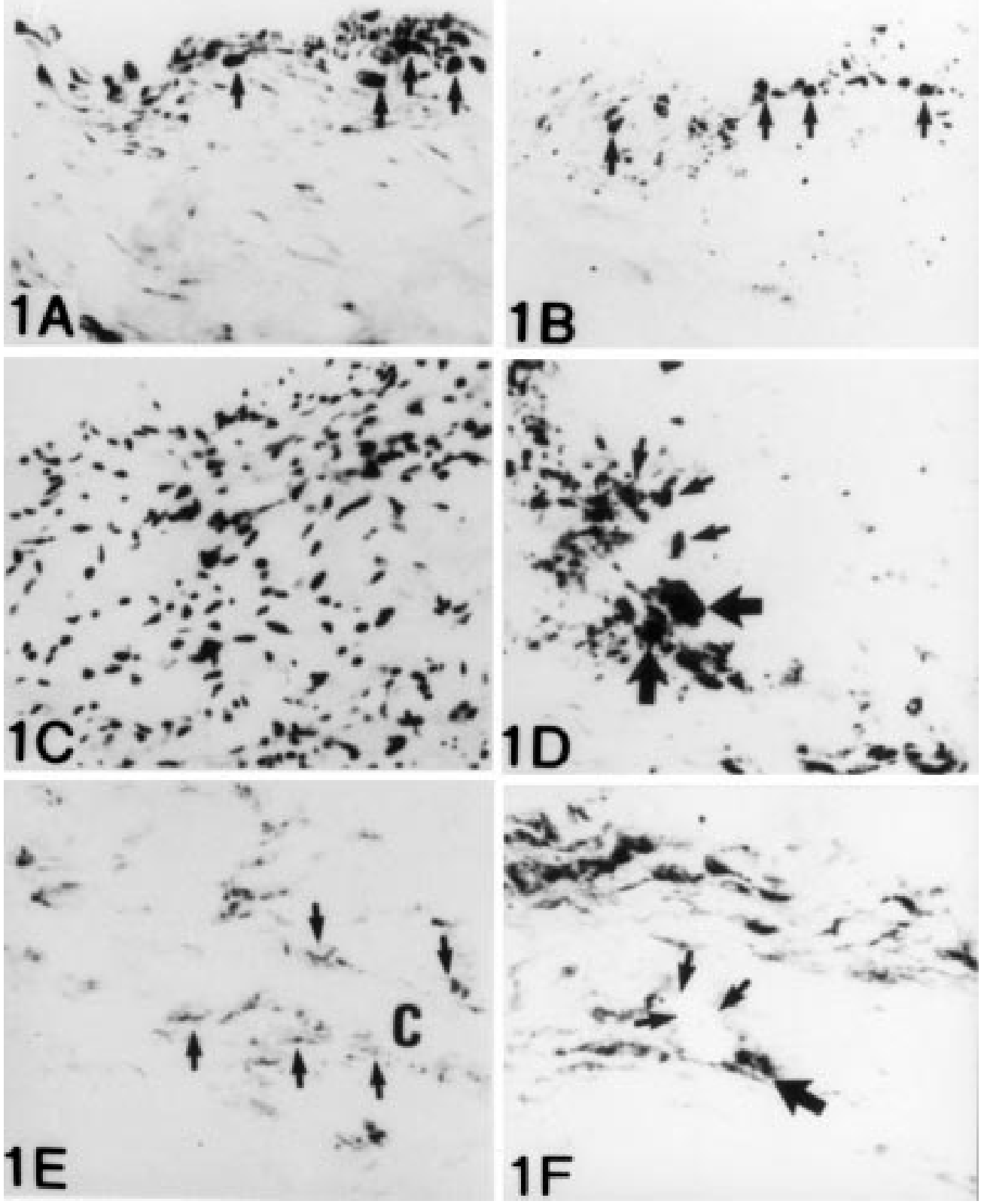

Figure 1 Immunostaining for epidermal growth factor $(E G F)(A)$ and transforming growth factor a $(T G F a)$ (B) in the synovial-like membrane from a patient with aseptic loosening of total hip arthroplasty. Macrophage staining, in particular, was strong and positive cells were almost restricted to the lining of layer of the interface toward the implant side (arrows). The histological features of this membrane were similar to those of synovial membrane from a patient with osteoarthritis (C). (D) Metal-containing macrophages (small arrows) or foreign body giant cells (larger arrows) were positively stained with EGF antibody. (E) Cement particulate debris, which was oval, was surrounded by macrophages which were positively stained with TGFa antibody. $(F)$ Polyethylene wear particles were surrounded by macrophages which were positively stained with TGFa antibody. (Figures $A, B, D, E$, F: original magnification $\times 250$, avidin-biotin-peroxidase complex staining, without counterstaining; fig C: original magnification $\times 250$, haematoxylin and eosin staining.)

in the interfacial membranes. Particulate debris detected included ultrahigh molecular weight polyethylene, polymethylmethacrylate, and metal wear. Metal particles were identified as irregularly shaped, fine $(2-10 \mu \mathrm{m})$, black particles. Small metal particles were often phagocytosed by macrophages/foreign body giant cells, but large particulate debris was often seen in the extracellular tissue (figs $1 \mathrm{~B}$ and D).Cement particles were usually larger and were surrounded by connective tissue and macrophages (fig $1 \mathrm{E}$ ). Polyethylene particles were identified as highly birefringent fine fragments when viewed under polarised light (fig $1 \mathrm{~F}$ ).
This interfacial membrane was often seen to invade periprosthetic bone tissue.

QUALITATIVE ASSESSMENT OF

IMMUNOHISTOCHEMICAL STAINING

In all samples the staining intensity varied between samples, but staining was similar throughout a sample. The slides were read by two of the authors (JWX and TFL).

Based on ordinary histological criteria, EGF was found in all interfacial membranes. EGF was found in macrophages/foreign body giant cells (figs $1 \mathrm{~A}$ and $\mathrm{D}$ ), fibroblasts (fig $2 \mathrm{~A}$ ), and vascular endothelial cells (fig $2 \mathrm{E}$ ). In particu- 

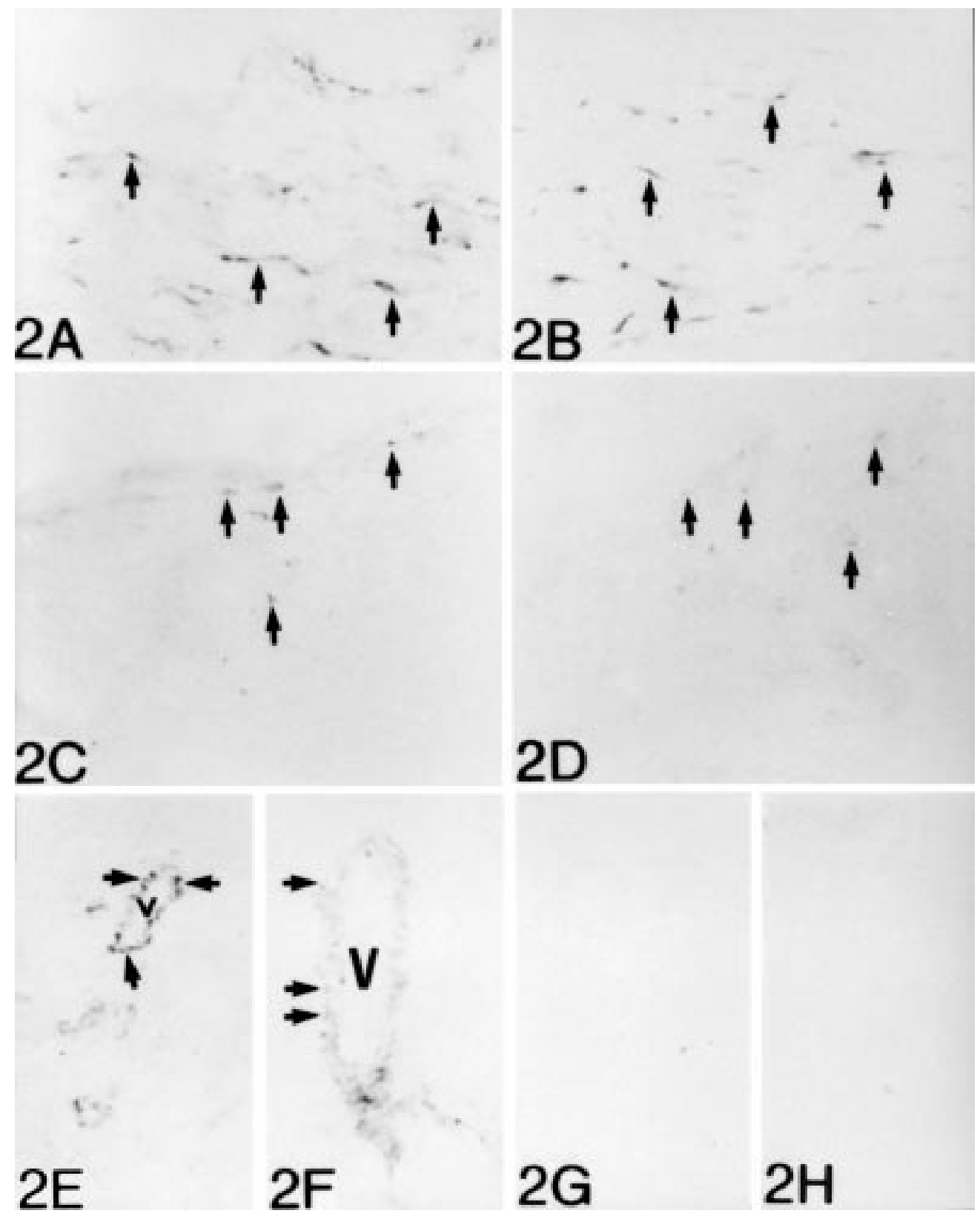

Figure 2 (A) Epidermal growth factor (EGF) and (B) transforming growth factor a (TGFa) positive fibroblasts in the synovial-like membrane from a patient with aseptic loosening of total hip arthroplasty. These microphotographs were of a relatively fibrous area, where the long and slender fibroblast-like cells predominate. In contrast with the EGF and TGFa staining in the synovial-like membrane from a patient with aseptic loosening of total hip arthroplasty, there were only a few $E G F(C)$ and TGFa (D) positive cells in the synovial membrane from patients with osteoarthritis who had undergone primary total hip arthroplasty, and staining was relatively weak. In addition to EGF and TGFa positive macrophages and fibroblasts seen in the synovial-like membrane, $E G F(E)$ and $T G F a(F)$ positive vascular endothelial cells (marked with arrows) were also found in this membrane. No $E G F(G)$ and $T G F a(H)$ positive cells were found in any of the staining controls obtained by using an avidin-biotin-peroxidase complex $(A B C)$ staining sequence, in which the primary antibody was omitted and replaced by same isotype IgG serum. (Original magnification $\times 250$, ABC staining, without counterstaining).

lar, all blood vessels were EGF positive. The result of $\mathrm{TGF} \alpha$ staining was similar to that for EGF. TGF $\alpha$ was also found in all interfacial membranes. Macrophages/foreign body giant cells (figs $1 \mathrm{~B}$ and $\mathrm{E}$ ), fibroblasts (fig $2 \mathrm{~B}$ ), and vascular endothelial cells (fig $2 \mathrm{~F}$ ) were found containing $\mathrm{TGF} \alpha$. The staining of $\mathrm{TGF} \alpha$ in vascular endothelial cells was relatively weak.

Synovial membranes from patients with OA contained few EGF and TGF $\alpha$ positive cells and staining was relatively weak (figs $2 \mathrm{C}$ and D), but with a similar cellular origin and distribution profile as for EGF and TGF $\alpha$ positive cells in the interfacial membranes. Staining control confirmed the specificity of all immunoreactions seen (figs $2 \mathrm{G}$ and $\mathrm{H}$ ).

IMAGE ANALYSIS

The number of EGF and TGF $\alpha$ positive cells was higher in the interfacial membranes than in the synovial membranes $(p<0.01$; table 2$)$. Although the numbers were too small for an adequate statistical comparison, there did not seem to be any particular differences between the type of fixation (with or without cement) or of alloy (TiVAl $v$ CoCrMo) used. 
Table 2. Epidermal growth factor (EGF) and transforming growth factor a (TGFa) expression as cells $/ \mathrm{mm}^{2}$ tissue analysed in interfacial membrane in loose total hip arthroplasty: comparison of interfacial membrane with synovial membrane from patients with osteoarthritis

\begin{tabular}{llll}
\hline Samples examined & $\begin{array}{l}\text { Number of } \\
\text { samples }\end{array}$ & $\begin{array}{l}\text { Cellularity } \\
\text { (EGF positive cells } \\
\text { (mean (SEM)) }\end{array}$ & $\begin{array}{l}\text { Cellularity } \\
\text { (TGFa positive cells } \\
\text { (mean (SEM)) }\end{array}$ \\
\hline $\begin{array}{l}\text { Interfacial membrane } \\
\text { Synovial membrane }\end{array}$ & 10 & $980(370)$ & $1070(360)$ \\
$270(100)$
\end{tabular}

For the difference between interfacial membrane and synovial membrane; $\mathrm{p}<0.01$.

\section{Discussion}

The results of our study confirm that EGF and $\mathrm{TGF} \alpha$ are produced at the interfacial membrane retrieved from a loose prosthesis. This study takes advantage of the staining done using the Lab Vision Autostainer, which makes the process easier and the results more reliable than by manual staining. Histopathological examination has shown that heterogeneity in tissue structure and cellularity within one sample and among tissue samples of different patients do exist in the interfacial membrane retrieved from a loose prosthesis at revision total hip arthroplasty. However, we used representative sampling for morphometric measurement of EGF and TGF $\alpha$ positive cells in this membrane and used statistics to show that the number of EGF and TGF $\alpha$ positive cells in this membrane was higher than in a synovial membrane from a patient with OA. This heterogeneity is probably due to the variable biological, mechanical, and material microenvironments along the interface. ${ }^{23}$

The evidence has shown that EGF and $\mathrm{TGF} \alpha$ stimulate bone resorption-for example, in mouse calvaria in organ culture, through a prostaglandin mediated mechanism. ${ }^{21}{ }^{24}$ In contrast, in fetal rat long bones, EGF and TGF $\alpha$ stimulate resorption by mechanisms that are independent of prostaglandin synthesis. ${ }^{19}{ }^{22} \mathrm{EGF}$ and TGF $\alpha$ also cause an increase of plasma calcium in mice ${ }^{25}$ and stimulate the formation of osteoclast-like cells in long term marrow cultures. ${ }^{26}$ The biological activities of EGF and TGF $\alpha$ are similar but not identical. For example, TGF $\alpha$ stimulates bone resorption to a much greater extent than EGF in organ cultures of fetal rat long bones. ${ }^{20} 27$

Much knowledge has accumulated on the biological mechanism whereby the wear debris leads to aseptic loosening. Macrophages/ foreign body giant cells phagocytose wear debris generated from prostheses, and this process in turn releases mediators that stimulate bone resorption. These mediators include prostaglandins, cytokines, metalloproteinases, lysosomal enzymes, nitric oxide, and others. ${ }^{135102829}$ In this study we have shown that both $\mathrm{EGF}$ and $\mathrm{TGF} \alpha$ were induced in cells, including macrophages/foreign body giant cells, fibroblasts, and endothelial cells in interfacial membranes. The greater number of EGF and TGF $\alpha$ positive cells in interfacial membranes than in synovial membranes suggests that local conditions induce EGF and TGF $\alpha$, capable of stimulating bone resorption and contributing to prosthetic loosening. EGF and $\mathrm{TGF} \alpha$ were found in different types of fixation (cemented and uncemented) and alloys (CoCrMo, TiAlV), suggesting that the same process of induced bone resorption contributes to aseptic loosening in all cases regardless of the differences in the type of fixation and alloy.

A major limitation of the study of interfacial membrane obtained at revision total hip arthroplasty for aseptic loosening is the absence of appropriate control samples. For ethical reasons it was not possible to obtain corresponding control samples from well fixed total hip arthroplasties. Goodman et al have studied cellular profile and cytokine production at interface tissue from well fixed prostheses. ${ }^{6}$ They concluded that the tissues from well fixed implants cannot be considered as controls, because these implants were painful, dislocating, or showed excessive polyethylene wear. Additionally, the time from implantation to revision for well fixed implants in both the cemented and cementless groups was shorter than for the respective groups with loosening. Thus the tissues surrounding well fixed prostheses were from prostheses in the early stages of failure, before more advanced mechanical and biological processes could produce loosening or osteolysis. Because it is impossible to find control samples which match the histopathological features of the interfacial membrane, we used synovial membrane obtained from patients with OA undergoing primary total hip arthroplasty to serve as control tissue in this study. As the histological features of interfacial membrane, or so called synovial-like membrane, ${ }^{1}$ are similar to those of synovial membrane from a patient with $\mathrm{OA}$, this seems appropriate.

In conclusion, we suggest that owing to their increased expression in interfacial membrane, $\mathrm{EGF}$ and $\mathrm{TGF} \alpha$ may have an important pathogenetic role in stimulating periprosthetic bone resorption in aseptic loosening of total hip arthroplasty. Additional research is necessary to improve understanding of EGF, TGF $\alpha$, and the complex cytokine network in interfacial membrane, which contribute to aseptic loosening of a total hip arthroplasty.

We thank Ms Eija Kaila and Mr Reijo Karppinen for skilful technical assistance, and Dr H Pätiälä at the Department of Orthopaedics and Traumatology, Helsinki University Central Hospital, for providing the samples used in this study.

Supported in part by grants from the Academy of Finland, Helsinki University Central Hospital, the Foundation for Orthopaedic and Traumatological Research in Finland.

1. Goldring SR, Schiller AL, Roelke M, Rourke CM, O'Neill DA, Harris WH. The synovial-like membrane at the bonecement interface in loose total hip replacements and its
proposed role in bone lysis. J Bone Joint Surg Am proposed role in

2 Jiranek WA, Machado M, Jasty M, Jevsevar D, Wolfe HJ, Goldring SR, et al. Production of cytokines around loosened cemented acetabular components. Analysis with mmunohistochemical techniques and in situ hybridization. J Bone Joint Surg Am 1993;75:863-79.

3 Takagi $M$. Neutral proteinases and their inhibitors in the loosening of total hip prostheses. Acta Orthop Scand 1996; 67(suppl 271):1-29.

4 Konttinen YT, Waris V, Xu JW, Jiranek WA, Sorsa T, Virtanen I, et al. Transforming growth factor- $\beta 1$ and 2 in the synovial-ike interface membrane between implant and 1997;24:694-701.

$5 \mathrm{Xu} \mathrm{JW,} \mathrm{Li} \mathrm{TF,} \mathrm{Partsch} \mathrm{G,} \mathrm{Ceponis} \mathrm{A,} \mathrm{Santavirta} \mathrm{S,}$ Konttinen YT. Interleukin-11 (IL-11) in aseptic loosening of total hip replacement (THE). Scand J Rheumatol 1998; of total hip
27:363-7. 
6 Goodman SB, Huie P, Song Y, Schurman D, Maloney W, Woolson S, et al. Cellular profile and cytokine production at prosthetic interfaces. J Bone Joint Surg Br 1998;80: 531-9.

7 Howie DW, McGee MA, Pearcy MJ. The response to particulate debris. Orthop Clin North Am 1993;24:57181.

8 Jacobs JJ, Shanbbag AS, Glant TT, Black J, Galante JO. Wear debris in total joint replacements. J Am Acad Orthop Surg 1994;2:212-20.

9 Maloney WJ, Smith RL. Periprosthetic osteolysis in total hip arthroplasty: the role of particulate wear debris. J Bone Joint Surg Am 1995;77:1448-61.

10 Konttinen YT, Xu JW, Pätiälä H, Imai S, Waris V, Li TF, et al. Cytokines in aseptic loosening of total hip replacement. Current Orthopaedics 1997;11:40-7.

11 Shanbhag AS, Jacobs JJ, Black J, Galante JO, Glant TT. Cellular mediators secreted by interfacial membranes obtained at revision total hip arthroplasty. J Arthroplasty 1995;10: at revision

12 Rubash HE, Sinha RK, Shanbhag AS, Kim SY. Pathogenesis of bone loss after total hip arthroplasty. Orthop Clin North Am 1998;29:173-86.

13 Goodman SB, Lind M, Song Y, Smith L. In vitro, in vivo, and tissue retrieval studies on particulate debris. Clin Orthop 1998;352:25-34.

14 Cohen S. Isolation of a mouse submaxillary gland protein accelerating incisor eruption and eyelid opening in the newborn animal. J Biol Chem 1962;237:1555-62.

15 DeLarco JE, Todaro GJ. Growth factors from murine sarcoma virus-transformed cells. Proc Natl Acad Sci USA 1978;75:4001-5.

16 Ebner R, Derynck R. Epidermal growth factor and transforming growth factor- $\alpha$ : differential intracellular routing and processing of ligand-receptor complexes. Cell Regulation 1991;2:599-612.

17 Derynck R. Transforming growth factor $\alpha$. Cell 1988;54 593-5.

18 Derynck R. The physiology of transforming growth factor- $\alpha$. Adv Cancer Res 1992;58:27-52.

19 Ibbotson KJ, Twardzik DR, D'Souza SM, Hargreaves WR, Todaro GJ, Mundy GR. Stimulation of bone resorption in vitro by synthetic transforming growth factor-alpha. Science 1985;228:1007-9.

20 Stern PH, Krieger NS, Nissenson RA, Williams RD, Winkle $\mathrm{ME}$, Derynck R, et al. Human transforming growth factoralpha stimulates bone resorption in vitro. J Clin Invest 1985;76:2016-19.

21 Tashiian Jr AH, Levine L. Epidermal growth factor stimulates prostaglandin production and bone resorption in cultured mouse calvaria. Biochem Biophys Res Commun 1978;85:966-75.

22 Raisz LG, Simmons HA, Sandberg AL, Canalis E. Direct stimulation of bone resorption by epidermal growth factor. Endocrinology 1980;107:270-3.

23 Goodman SB, Knoblich G, O'Connor M, Song Y, Huie P, Sibley R. Heterogeneity in cellular and cytokine profiles from multiple samples of tissue surrounding revised hip prostheses. J Biomed Mater Res 1996;31:421-8.

24 Tashjian AH Jr, Voelkel EF, Lazzard M, Singer FR, Roberts $\mathrm{AB}$, Derynck R, et al. $\alpha$ and $\beta$ human transforming growth factors stimulate prostaglandin production and bone resorption in cultured mouse calvaria. Proc Natl Acad Sci USA $1985 ; 82: 4535-8$

25 Tashiian AH Jr, Voelkel EF, Lloyd W, Derynck R, Winkler $\mathrm{ME}$, Levine L. Actions of growth factors on plasma calcium. J Clin Invest 1986;78:1405-9.

26 Takahashi N, MacDonald BR, Hon J, Winkler ME, Derynck R, Mundy GR, et al. Recombinant human transforming growth factor-alpha stimulates the formation of forming growth factor-alpha stimulates the formation of osteoclast-like cells in long-tern
Clin Invest 1986;78:894-8.

27 Ibbotson KJ, Harrod J, Gowen M, D'Souza S, Smith DD, Winkler ME, et al. Human recombinant transforming growth factor $\alpha$ stimulates bone resorption and inhibits formation in vitro. Proc Natl Acad Sci USA 1986;83:2228-32.

28 Santavirta S, Sorsa T, Konttinen YT, Saari H, Eskola A, Eisen AZ. Role of mesenchymal collagenase in the loosening of total hip prosthesis. Clin Orthop 1993;290:206-15.

29 Huklanen M, Corbett SA, Platts LAM, Kontinen YT, Santavirta S, Hughes SPF, et al. Nitric oxide in the local host tavirta S, Hughes SPF, et al. Nitric oxide in the local host 53-65. 